\title{
A Conceptual Framework for Trust-building to Promote Teacher Leadership
}

\author{
Bryan S. Zugelder (Corresponding Author) \\ Dept. of Elementary Education and Middle Grades Education, East Carolina University \\ 154 Speight Building, Greenville, NC 27858, United States \\ Tel: 1-252-737-1704_E-mail: zugelderb16@ecu.edu \\ B. Grant Hayes \\ Office of the Dean, East Carolina University \\ 154 Speight Building, College of Education, Greenville, NC 278585, United States \\ Tel: 1-252-328-4260_E-mail: hayesb15@ecu.edu
}

Received: March 22, 2019

doi:10.5296/jet.v6i2.14530
Accepted: April 8, 2019

Published: April 9, 2019

URL: http://dx.doi.org/10.5296/jet.v6i2.14530

\begin{abstract}
This article proposes a conceptual framework for building trust between principals and teachers for the purpose of empowering teacher leaders within a school environment. While instructional leadership is the ultimate responsibility of the school principal, researchers have recognized they cannot perform alone. Therefore, it is necessary for principals to build trust with teachers. The concept of principal and teacher trust appears throughout educational leadership research; however, a clear conceptual framework which demonstrates a method for creating and ensuring trust can be used as a teaching tool in principal and teacher leadership preparation. Implications for research include testing and validating the framework, while investigating findings on its effectiveness.
\end{abstract}

Keywords: Instructional leadership, Teacher leadership, Principal trust, Teacher trust, shared leadership

\section{Introduction}

Teacher leadership is not confined to formal roles (Danielson, 2007). In fact, all teachers in one part of the United States are expected to demonstrate some level of teacher leadership to earn at least a proficient evaluation rating on the state's teacher performance appraisal (North Carolina Department of Public Instruction, 2013). Teacher leadership has come back to the forefront of conversations as a teacher retention strategy, especially as attrition continues to surface in nearly every corner of the nation. While providing teacher leadership can be used as a teacher retention strategy, empowering teachers to be leaders is a transformational leadership paradigm 
that enacts intentional behavior on the part of the principal for the sake of motivating teachers to see their purpose (Lee \& Kuo, 2019; Nedelcu, 2013). Consequently, a collaborative school vision has potential to spark leadership behaviors from teachers, exhibited within their classroom walls and beyond (Neumerski, 2013; Sterrett, 2016; Warren \& Sugar, 2005).

Teacher leadership is not possible without a culture of trust established by the school principal (Garmston \& Wellman, 2016). Elements of principal and teacher trust are found in the literature as a basis for transformational leadership, specifically the importance of why trust must exist to build an effective school climate (Nedelcu, 2013). Dissecting the interactions of a trusting environment is important; however, there is lack of a clear visual framework on the teaching of trust-building, combining the essential components of developing and implementing trusting school environments. Therefore, this article proposes a conceptual framework, grounded in a comprehensive review of literature, to help principals build shared leadership across a professional school community as a tool to enhance teacher leadership, ultimately shaping a healthy organizational culture.

\section{Literature Review}

This article is grounded in a theoretical orientation that all teachers are leaders. Additionally, shared instructional leadership among teachers and principals has promise for positive effects on school climate (Boyce \& Bowers, 2018). This type of distributive leadership (Klar, 2012) is found predominantly in the concepts of an adaptive school, where multiple educator stakeholders work together to impact teaching and learning, taking on various formal and informal roles (Garmston \& Wellman, 2016). Shared instructional leadership is a transformational practice, where principals and teachers work together, collaboratively, for matters involving curriculum, teaching, and learning (Garmston \& Wellman, 2016; Urick, 2016). The review of literature was conducted using the theoretical orientation of shared instructional leadership, drawing on elements of principal instructional leadership, teacher empowerment, and trust between principals and teachers.

\subsection{Shared Instructional Leadership}

Shared instructional leadership has been found as the most effective leadership style, as reported by Urick (2016) in findings related to various leadership practices. Urick (2016) discovered that shared instructional leadership, where leaders identified with Marks and Printy's (2003) style of effectively engaging teachers in instructional decision making, was the most likely leadership style to influence positive motivation, which led to better outcomes on teacher retention. This included teachers' view of principals as possessing limited centralized leadership and where teachers felt freedom to contribute significant input to the problems of school matters pertaining to teaching and learning. While teachers recognized the principal's role as instructional leader, they also believed their voices mattered because the principal set the tone. This idea of collective and collaborative problem-solving was also recommended by Garmston and Wellman (2016).

Hallinger and Murphy (2013) examined barriers to principal's sole ability to lead instruction, including limited time and expertise. The burden of student achievement for the school community falls on the shoulders of the school principal, but leading effective teaching and 
learning involves vertical and horizontal collaboration stemming from the principal's vision of high quality (Taylor, 2010). The idea of shared instructional leadership, where teachers and principals engage as important team members to improve the quality of instruction was found in key research articles. Sharing the responsibility lifts the burden from one and empowers the team as a whole. A heterarchical model of leadership, rather than hierarchical, led to high levels of collaboration in schools (Stephenson, 2009). Heterarchical leadership is a frame where organizational reporting is flat and not hierarchical. However, Nguyen, Ng, and Yap. (2017) discovered that tinges of hierarchy and heterarchy were both important, since principals played a key role in school structure, leading to the development of a healthy school climate. Most importantly is the conception of collective leadership, where multiple players are involved, with multiple perspectives (Leithwood, Harris, \& Hopkins, 2008).

A key competency of school principals, instructional leadership, is to effectively drive decisions that ensure student success (National Policy Board for Educational Administration, 2015). While instructional leadership is a responsibility of school principals, they must empower teachers to engage in leadership opportunities that influence instructional decisions within the classroom, school, and greater community (Hallinger \& Murphy, 2013; Mangin \& Stoelinga, 2010; National Education Association, 2011; Tschannen-Moran \& Gareis, 2015). Rafoth and Foriska (2006) highlighted an interactive model of school leadership, where principals engage their teachers in shared decision making. This type of transformational leadership led to improved problem solving and empowerment of teachers, consistent with other bodies of research (Garmston \& Wellman, 2016; Hallinger \& Murphy, 2013; Tschannen-Moran \& Gareis, 2015).

\subsection{Empowerment and Trust}

Empowerment is a crucial component in building teams. Healthy school cultures, where teachers are not only recognized for their accomplishments, but are also given responsibility, keep the best teachers engaged (Browne-Ferrigno, 2016). Formerly known as The New Teacher Project, TNTP (2012) reported that principals who do not create "a professional environment where the best teachers are excited to work...find it much more difficult to retain their best teachers" (p. 18). Making teachers feel empowered builds upon their innate leadership abilities. More importantly, teachers who feel empowered are excited to work, because they have bought into a vision to which they very much feel attached. Teacher empowerment, however, requires trust between the principal and the teacher (Printy \& Marks, 2006). Tschannen-Moran (2014) declared that trust is the main ingredient necessary in teacher and principal relationships, which leads to a shared organizational vision. Tschannen-Moran and Gareis (2015) further uncovered that teachers' trust in the principal was the most essential component of a high-performing school.

Individuals working together requires mutual trust, and when truly existent, the ultimate result is school improvement (Tschannen-Moran \& Hoy, 2001). Mutual trust stems from mutual respect (Handford \& Leithwood, 2013). Trust can be difficult, especially when principals hold evaluative leverage over the teachers they supervise (DiPaola \& Hoy, 2008). Establishing employee-supervisor trust is a delicate dance of art and science, with potential to yield organizational effectiveness, specifically student success. Kwan (2016) confirmed 
statistical significance in correlating relational trust between the principal and teachers as the most effective instructional leadership practice. In schools with higher levels of trust, student achievement was positively impacted, where teachers felt more committed to the environment.

\section{Conceptual Framework}

As Yost, Vogel, and Rosenberg (2009) found, the "most important aspect of working with teachers is establishing trusting relationships..." (p. 23). Trust is neither given nor received easily; rather, it is earned. Trust is an essential component of any relationship, and it takes actionable effort and time to build. In order for a trusting environment to exist, several conditions on principal and teacher trust can be categorized into four major sub-themes, confirmed by a rich body of research and organized into one concept. These sub-themes have been categorized as the core of the proposed framework, which include:

- $\quad$ self-awareness and authenticity;

- consistent and meaningful interpersonal interactions;

- cultivation of school professionalism and community; and

- culture of honesty.

To enact shared school leadership, where teachers and principals make collaborative decisions about curriculum and study school problems together in a professional learning community, trust must exist at the core of all relationships (Garmston \& Wellman, 2016).

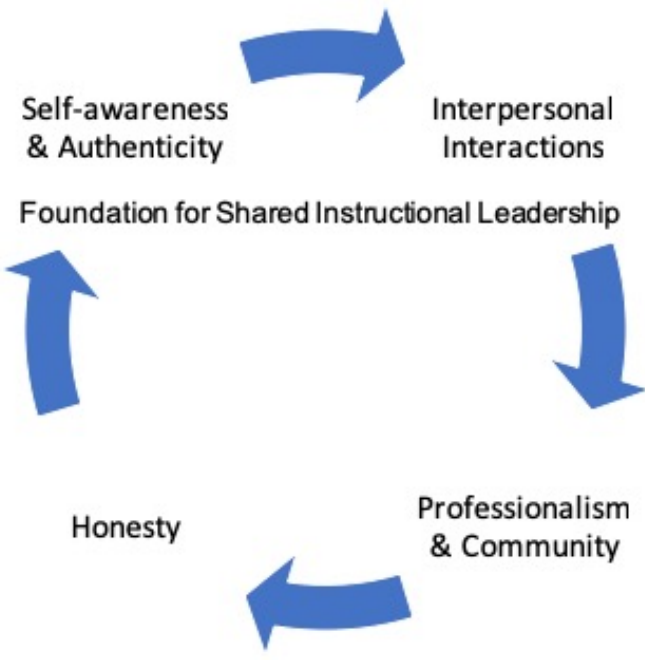

Figure 1. Conceptual framework for trust-building

As a tool for teaching and research, we propose a visual, conceptual framework for trust-building, based on concepts drawn from research on instructional leadership, shared leadership, and principal-teacher trust. Figure 1 demonstrates a cyclical process, rather than linear, as the basis for enacting shared instructional leadership through the lens of trust-building. Each part of the framework is equally important; therefore, entry points are not intended to occur in chronological order. A leader must understand the context of his or her 
environment and make sound decision as to which element is important at a given point in time. Simultaneous action across the framework is recommended.

The framework, while centered on the ultimate goal of shared instructional leadership, dives deep into the concepts of intentional work on trust-building. As confirmed by Tschannen-Moran and Gareis (2015), trust is the most important component of a high-performing school.

\subsection{Self-awareness and Authenticity}

Effective leadership requires deliberate and intentional approaches to nurture and foster relationships at all levels. When human beings occupy leadership positions, they inadvertently expose their flaws at an amplified level (Maxwell, 2014). It is essential that principals understand their flaws and embrace them; the same is true for teachers. Recognizing that all humans carry some form of baggage is necessary and introspectively understanding one's own baggage creates a strong sense of self-awareness.

Understanding one's self leads to authenticity in leadership, where words and actions are congruent (Wang \& Bird, 2011). It is not possible to understand and develop people without first understanding self (Leithwood, Day, Sammons, Harris, \& Hopkins., 2006). This leadership maturity becomes a model for teachers, so they can understand themselves as individuals, which is a key step in developing leadership qualities. True development occurs when the setting of good examples becomes the norm, and this eventually transcends to student behaviors (Bruttencate, Luyten, Scheerens, \& Sleegers, 2012).

The ultimate reward of self-awareness is authenticity in leadership. When a leader is authentic, everyone knows. School principals who model authenticity create teacher leaders who are also authentic. A culture of self-awareness and authenticity sets a strong foundation for trust (Wang \& Bird, 2011). It is when teachers and leaders trust each other that true reform takes place. The best leaders are those who create more leaders, and they do so through sharing leadership responsibility.

\subsection{Consistent and Meaningful Interpersonal Interactions}

Trusting relationships form from healthy interpersonal interactions (Moye, Henkin, \& Egley, 2004). In a work environment, trusting relationships are essential, because they lead to empowerment. For a teacher to be empowered by a principal to use his or her strengths, there has to be a well-established interpersonal baseline of interaction. When a teacher feels that the principal trusts him or her, barriers are eliminated. Equally important is that teachers must feel a sense of belonging to the organizational environment, if they are to have the deepest level of meaningful interactions with anyone at the school. It is essential that principals create this sense of belonging among their teachers to foster a healthy environment of human interaction (Fox, Gong, \& Attoh, 2015).

Consistent interpersonal interactions are necessary, because they demonstrate patterns in behaviors. When a principal exhibits predictable and approachable behaviors, teachers feel safe to interact with them. Most importantly, trusting teacher-principal relationships lead to a positive impact on student achievement (Price, 2015). Furthermore, the time spent on 
developing relationships through meaningful interpersonal interactions is necessary and well-worth the investment. Social interactions have proven to have some impact on developing trust, as outlined in literature (Price, 2015). Only those interactions that are inwardly focused on context of the organization, however, demonstrate "support and trust in teachers...[having]...lasting effects on the latent beliefs and perceptions that influence teachers' work..." (p. 130).

Consequently, for a teacher to demonstrate leadership qualities, he or she must also be consistent in interactions with colleagues. This should be modeled by the principal to create transference of behaviors throughout the school. Interpersonal interactions that lead to common bonds among the team create a sense of freedom to share ideas, fostering appreciation of the unique contributions of all. The most influential way to build relationships is by spending time with one other, especially among those who do not always agree (Bolman $\&$ Deal, 2010). The more consistent and healthier the interactions, where disagreements turn to understandings, bonding ensues.

Interactions among teachers and between teachers and leaders also create a common set of shared values. High-leverage interactions are focused on student learning, developing curriculum, and talking about teaching and learning practices (Wahlstrom \& Louis, 2008). This multi-level system of interaction creates a shared leadership among the school community, empowering all teachers to use their natural leadership abilities at various times, through multiple roles, and from many diverse angles.

\subsection{Cultivation of Professionalism and Community}

Consistent and meaningful interpersonal interactions should be deliberate in establishing a culture of professionalism. All teachers are leaders; therefore, their exhibited behaviors are analogous to any profession with high societal standards, like lawyers, doctors, judges, and clinicians. For teachers to exhibit the true leadership qualities expected of them by the public, a culture of professionalism must be the norm. Appropriate modeling by the principal filters throughout all facets of the school.

To ensure a culture of professionalism, there must be opportunities for teachers and leaders to work together. A key component of a professional school environment is when colleagues study what works, based on evidence; this ultimately leads to the true meaning of a professional learning community (Tschannen-Moran, 2009). For school-related problems to be studied, an environment where all school professionals feel safe to express their professional opinions must be part of the cultural norms. In turn, instructional improvement becomes a shared goal.

A culture where poor teaching practice is not tolerated is also based on this ongoing professional study of contextual issues of the school (Tschannen-Moran, 2009). When all voices are heard, and fair treatment of all of those voices are at play, a community of professionalism breeds a culture of mutual respect (Handford \& Leithwood, 2013). Additionally, professional dialogue is focused on problem-solving among all stakeholders, for the sake of collectively improving the school. 
Collective voices create an important level of leadership, where matters of instruction are shared. When leadership is shared, principals and teachers both take ownership of the school and deeply care about making it a better learning organization. When teachers are empowered by each other and by school administrators, they support each other in a trusting professional community. Additionally, they often take on roles, where they are seen as the leader, as professional dialogue results in appreciation of the unique strengths each offer to the school (Walhstrom \& Louis, 2008).

\subsection{Culture of Honesty}

For more than three decades, Kouzes and Posner (2017) have reported on the desired characteristics that employees look for in their leaders, over a period of six studies. Consistently, honesty has been the top-rated attribute that people look for most in a leader. Although often difficult is the honest disclosure of data, especially when results are not favorable. A principal who makes all data transparent helps to build trust among all members of the school, even when the data are not impressive... and even when the data might reflect areas where leadership should improve (Taylor, 2010). This practice of honesty reinforces a culture of professionalism, where the ongoing study of what works in teaching and learning is examined.

When a principal is willing to expose less-than-popular data in a non-defensive, problem-focused manner, even about the school climate ultimately under her responsibility, trust builds from the open and honest conversations that follow. In turn, teachers are willing to examine their own data with the goal of improving their practice. Tschannen-Moran (2009) found that a culture of honesty is one that embraces when teachers admit their struggles, and when teachers are not ashamed to admit when their practices did not produce desired results. This public transparency and risk-taking encourages more honesty and openness, ultimately leading to trust. Such tone is set, however, by the principal. Conversations about data can be difficult for teachers. When the conversations are built around a culture of honesty, they become easier to tackle, especially when the principal also models the willingness to look inward. Honesty about matters of the school are critical, as are honest introspection and individual reflection.

\section{A Holistic Approach}

Each component of the conceptual framework is equally important. We hypothesize that the components must be intertwined in order to be implemented effectively. For example, cultivating a culture of honesty cannot be accomplished without authentically nurturing and fostering healthy interpersonal interactions. Entry points to the conceptual framework are not linear and depend upon contexts that include micro- and macro-environmental considerations. Furthermore, because we view shared instructional leadership as multi-dimensional, trust-building is also multi-dimensional, requiring ongoing and deliberate attempts to achieve all components of the framework. Leaders may use the conceptual framework as a tool for self-assessment, but also as an assessment of the bigger picture of the organization. 
Applying the components of the framework is highly dependent upon the modeling principals do for teachers, ultimately inspiring leadership among all. For a principal to first demonstrate self-awareness and authenticity, it is critical that principals take steps to understand who they are as individuals and who they are as professionals. There are multiple inventories on the market, such as the Myers-Briggs Type Indicator (Myers \& Briggs Foundation, 2019), where principals can understand their own personalities, which can be helpful for them to further understand the personalities of the teachers with whom they work. Understanding oneself is necessary to attain authentic, congruent actions that match belief and value systems. It is our contention that one must know himself or herself before effectively leading a group of professionals.

It is also our belief that principals who have a strong sense of self-awareness are willing to reflect upon their personal strengths and areas for improvement. They must maintain an inner circle of trusted colleagues, which may include other principals and mentors who can help them reflect honestly about themselves so that they maintain the healthiest understanding of who they are. Principals who demonstrate this level of self-understanding will model for those with whom they have influence to do the same. Because the burden of leadership is great, establishing a strong foundation of self-knowledge is key to implementing this framework. Ongoing self and organizational reflection in relationship to the elements of the framework is critical to successful implementation.

To establish, nurture, and maintain healthy and meaningful interpersonal interactions, principals must intentionally work toward achieving this as a cultural norm. While teambuilding activities, whether formal or informal, are helpful, they must actively facilitate interactions that elevate professional dialogue, as noted in the research, that keeps the context of the organization at the core (Price, 2015). Intentional scheduling of interactions where teachers have opportunities to share and reflect about classroom and school matters, individually and in group settings, is essential to continue the building of effective interpersonal interactions. Additionally, the more principals understand their teachers' individual personalities, beliefs, and aspirations, is necessary to ensure ongoing interpersonal interactions that result in reciprocal benefits.

Because healthy and meaningful interpersonal interactions are at the core of effective group dynamics, a community of professionalism, combined with the embracing of a culture of honesty, naturally endure throughout the process of implementing the conceptual framework. The cyclical nature of the framework lends itself to honesty when self-awareness and authenticity are practice. Additionally, honesty develops when professional communities examine problems grounded in data, related to professional practice. This includes studying school-level outcomes, grade-level outcomes, and analyzing lesson effectiveness together. Honesty must also be acceptable throughout interpersonal interactions, where team members hold each other accountable for feeling safe enough to share their ideas and thoughts pertaining to the organization. In turn, a professional community, where problems are viewed as a group, lead to collaborative solutions for the greater good of the school organization. 
5. Research Implications

The purpose of the holistic conceptual framework is that much of the literature refers to trust as a key ingredient in transformational leadership attributes and interpersonal relationships within school organizations. Furthermore, shared instructional leadership relies greatly on interpersonal relationships and collegial interactions. Developing and nurturing trust may have implications on developing effective shared instructional leadership.

As a next step in researching the conceptual framework, we recommend the development of a valid and reliable rubric to assess the extent to which each component is demonstrated by the teacher as leader and by the principal. Potential use of a rubric may be in the form of an observation tool or a questionnaire to determine the perceptions of both principals and teachers. Additionally, focus groups providing the opportunity for further examination of teacher perceptions would be a central focus to identify findings related to the development of shared instructional leadership and if key themes of trust-building emerge from such findings. The combination of quantitative and qualitative findings may inform the fields of teacher education, teacher development, teacher leadership, and principal preparation. Teacher educators working with principal educators to prepare practitioners would be an effective practice aligned with this research.

\section{Conclusion}

As we have argued, teacher leadership is not confined to a specific role. All teachers are leaders; however, a principal's approach to building capacity is key in developing the innate leadership abilities of the teachers in a school. When school principals recognize their buildings are filled with experts who have first-hand knowledge of the multi-faceted environments, they manage each day, a trusting team environment emerges. While principals are charged with the responsibility of being the instructional leader of the school, they must also recognize they cannot do it alone. Creating a community of trust, where teachers interact with each other and bring their unique perspectives and expertise to the table, has potential to nurture shared instructional leadership.

\section{References}

Bolman, L. G., \& Deal, T. E. (2010). Reframing the path to school leadership: A guide for teachers and principals (2nd ed.). Thousand Oaks, CA: Corwin Press.

Boyce, J., \& Bowers, A. J. (2018). Toward an evolving conceptualization of instructional leadership as leadership for learning: Meta-narrative review of 109 quantitative studies across 25 years. Journal of Educational Administration, 56(2), 161-182. https://doi.org/10.1108/jea-06-2016-0064

Browne-Ferrigno, T. (2016). Developing and empowering leaders for collective school leadership. Journal of Research on Educational Leadership, 11(2), 151-157. https://doi.org/10.1177/1942775116658820

Bruttencate, G., Luyten, H., Scheerens, J., \& Sleegers, P. (2012). Modeling the influence of school leaders on student achievement: How can school leaders make a difference? 
https://doi.org/10.1177/0013161x11436272

Danielson, C. (2007). The many faces of leadership. Educational Leadership, 65(1), 14-19.

DiPaola, M. F., \& Hoy, W. K. (2008). Principals improving instruction: Supervision, evaluation, and professional development. Boston: Pearson.

Fox, J., Gong, T., \& Attoh, P. (2015). The impact of principal as authentic leader on teacher trust in the K-12 educational context. Journal of Leadership Studies, 8(4), 6-18. https://doi.org/10.1002/jls.21341

Garmston, R. J., \& Wellman, B. M. (2016). The adaptive school: A sourcebook for developing collaborative groups (3rd ed.). Lanham, MD: Rowman \& Littlefield.

Hallinger, P., \& Murphy, J. F. (2013). Running on empty? Finding the time and capacity to lead learning. NASSP Bulletin, 97(1), 5-21. https://doi.org/10.1177/0192636512469288

Handford, V., \& Leithwood, K. (2013). Why teachers trust school leaders. Journal of Educational Administration, 51(2), 194-212. https://doi.org/10.1108/09578231311304706

Klar, H. W. (2012). Fostering distributed instructional leadership: A sociocultural perspective of leadership development in urban high schools. Leadership and Policy in Schools, 11(4), 365-390. https://doi.org/10.1080/15700763.2012.654886

Kouzes, J. M., \& Posner, B. (2017). The leadership challenge (6th ed.). San Francisco: Jossey-Bass.

Kwan, P. (2016). The effect of trust on the relationship between instructional leadership and student outcomes in Hong Kong secondary schools. The Asia-Pacific Education Researcher, 25(1), 111-121. https://doi.org/10.1007/s40299-015-0242-5

Leithwood, K., Day, C., Sammons, P., Harris, A., \& Hopkins, D. (2006). Successful school leadership: What it is and how it influences student learning (Research Report 800). London, UK: Department for Education.

Leithwood, K., Harris, A., Hopkins, D. (2008). Seven strong claims about successful school leadership. School Leadership and Management, 28(1), 27-42. https://doi.org/10.1080/13632430701800060

Mangin, M. M., \& Stoelinga, S. R. (2010). The future of instructional teacher leader roles. The Educational Forum, 74(1), 49-62. https://doi.org/10.1080/00131720903389208

Marks, H. M, \& Printy, S. M. (2003). Principal leadership and school performance: An integration of transformational and instructional leadership. Educational Administration Quarterly, 39(3), 370-397. https://doi.org/10.1177/0013161x03253412

Maxwell, J. C. (2014). The 21 indispensable qualities of a leader. Duluth, GA: The John Maxwell Company.

Moye, M. J., Henkin, A. B., \& Egley, R. J. (2005). Teacher-principal relationships: Exploring 
linkages between empowerment and interpersonal trust. Journal of Educational Administration, 43(2/3), 260-277. https://doi.org/10.1108/09578230510594796

Muijs, D., \& Harris, A. (2006). Teacher led school improvement: Teacher leadership in the UK. Teaching and Teacher Education, 22(8), 961-972. https://doi.org/10.1016/j.tate.2006.04.010

Myers \& Briggs Foundation (2019). MBTI basics. [Online] Available: https:/www.myersbriggs.org/my-mbti-personality-type/mbti-basics/home.htm?bhcp=1 (April $5,2019)$

National Education Association (2011). Teacher leader model standards. [Online] Available http://www.nea.org/home/43946.htm (March 24, 2019)

National Policy Board for Educational Administration. (2015). Professional standards for educational leaders 2015. Reston, VA: Author.

Nedelcu, A. (2013). Transformational approach to school leadership: Contribution to continued improvement of education. Manager, 17(1), 237-244.

Neumerski, C. M. (2012). Rethinking instructional leadership, a review: What do we know about principal, teacher, and coach instructional leadership and where should we go from here? Educational Administration Quarterly, 49(2), 310-347. https://doi.org/10.1177/0013161x12456700

Nguyen, D. T., Ng, D., \& Yap, P. S. (2017). Instructional leadership structure in Singapore: A co-existence of hierarchy and heterarchy. Educational Administration, 55(2), 147-167. https://doi.org/10.1108/jea-05-2016-0060

North Carolina Department of Public Instruction. (2013). North Carolina professional teaching standards [adopted 1998, revised 2013]. [Online] Available: http://www.ncpublicschools.org/docs/effectiveness-model/ncees/standards/prof-teach-standar ds.pdf (March 24, 2019)

Price, H. E. (2015). Principals' social interactions with teachers: How principal-teacher social relations correlate with teachers' perceptions of student engagement. Journal of Educational Administration, 53(1), 116-139. https://doi.org/10.1108/jea-02-2014-0023

Printy, S. M., \& Marks, H. M. (2006). Shared instructional leadership for teacher and student learning. Theory into Practice, 45(2), 125-132. https://doi.org/10.1207/s15430421tip4502_4

Rafoth, M. A., \& Foriska, T. (2006). Administrator participation in promoting effective problem-solving teams. Remedial and Special Education, 27(3), 130-135. https://doi.org/10.1177/07419325060270030101

Sanborn, M. (2006). You don't need a title to be a leader. New York: The Crown Publishing Group.

Stephenson, K. (2009). Neither hierarchy nor network: An argument for heterarchy. People and Strategy, 32(1), 4-7. https://doi.org/10.1007/978-3-658-21742-6_108 
Taylor, R. T. (2010). Leading learning: Change student achievement today! Thousand Oaks, CA: Corwin Press.

TNTP. (2012). The irreplaceables: Understanding the real retention crisis in America's urban schools. [Online] Availble: https://tntp.org/assets/documents/TNTP_Irreplaceables_2012.pdf (March 24, 2019)

Tschannen-Moran, M. (2014). Trust matters: Leadership for successful schools. San Francisco: Jossey-Bass.

Tschannen-Moran, M. (2009). Fostering teacher professionalism in schools: The role of leadership orientation and trust. Educational Administration Quarterly, 45(2), 217-247. https://doi.org/10.1177/0013161x08330501

Tschannen-Moran, M., \& Gareis, C. R. (2015). Faculty trust in the principal: An essential ingredient in high-performing schools. Journal of Educational Administration, 53(1), 66-92. https://doi.org/10.1108/jea-02-2014-0024

Tschannen-Moran, M., \& Hoy, W. K. (2000). A multidisciplinary analysis of the nature, meaning, and measurement of trust. Review of Educational Research, 70(4), 547-593. https://doi.org/10.3102/00346543070004547

Wahlstrom, K. L., \& Louis, K. S. (2008). How teachers experience principal leadership: The roles of professional community, trust, efficacy, and shared responsibility. Educational Administration Quarterly, 44(4), 458-495. https://doi.org/10.1177/0013161x08321502

Wang, C., \& Bird, J. J. (2011). Multi-level modeling of principal authenticity and teachers' trust and engagement. Academy of Educational Leadership Journal, 15(4), 125-147.

Yost, D. S., Vogel, R., \& Rosenberg, M. D. (2009). Transitioning from teacher to instructional $\begin{array}{llll}\text { leader. Middle School } & \text { Journal, }\end{array}$ https://doi.org/10.1080/00940771.2009.11495583

\section{Copyright Disclaimer}

Copyright reserved by the author(s).

This article is an open-access article distributed under the terms and conditions of the Creative Commons Attribution license (http://creativecommons.org/licenses/by/3.0/). 